\title{
CONCEPTUALISATION OF AN ETHICAL RISK ASSESSMENT FOR HIGHER EDUCATION INSTITUTIONS
}

\author{
A. Grobler \\ Area Head: Leadership and Organisational Behaviour \\ Graduate School for Business Leadership* \\ e-mail: grobla@unisa.ac.za
}

\author{
A. L. Horne \\ Human Resource Development Specialist* \\ e-mail: horneal@unisa.ac.za \\ *University of South Africa \\ Pretoria, South Africa
}

ABSTRACT

This article examines an ethical risk assessment conducted in one of South African largest higher education institutions, with the purpose to provide a confirmed structure and conceptualisation of ethical risks to be used within the Higher Education sector. A statistical analysis of 1687 respondents participating in the original ethical risk assessment survey was conducted. Confirmatory factor analyses supported a higher order, multidimensional model of three main factors, namely institutional ethical leadership orientation, individuallemployee ethical orientation and institutional student-centerednesslorientation. Based on this examination and analysis this three-factor structure provides sufficient evidence of a conceptual ethical framework to be used as basis of ethical risk assessments by higher education institutions.

Keywords: conceptual ethical framework, ethical risk assessment, ethics risk questionnaire, ethical virtue cultures, ethical climate criteria, higher education institutions.

\section{INTRODUCTION}

The obligation of higher education institutions to uphold sound ethical values and to foster an ethical culture has become more important than ever. This renewed consciousness and realisation is mainly a result of the changing landscape of higher education. Increase pressure is placed on these institutions to function like businesses than autonomous academic entities (Chapman and Chien 2014). Institutions are increasingly acutely aware of their responsibility to ensure that their strategy is well resources and executed, whilst maintaining robust risk management to manage failures (Shah and Nair 2014). Failures such as lack of financial 
oversight and accountability (Prisacariu and Shah 2016), susceptibility to corruption such as nepotism, undue influence, conflict of interest, misappropriation of funds, etc. (Chapman and Lindner 2016) have a direct impact on institutions strategic priorities of student centeredness and providing high quality education. Thus the notion of upholding good corporate governance to keep universities credibility intact is of fundamental importance. Testimony to this is the introduction of new legislation based on King III recommendations requiring higher education institutions in South Africa to promote good governance through sound leadership, sustainability and corporate citizenship (Republic of South Africa 2012) through sound ethical values of responsibility, accountability, fairness and transparency (The King III Report 2009). This notion is also captured in the King IV that was published in 2016. The South African Higher Education domain has been rocked by the \#feesmustfall movement, which brought further attention to the way in which institutions manage itself, and specifically how they govern themselves in order to address the external challenges in a responsible, transparent and effective manner to ensure sustainability.

Ethical risk assessments is an important element of corporate governance, and it is required that organisations and institutions develop the ability to conduct their own ethical risk assessment (The King III Report 2009). In many instances risk assessments are conducted to determine ethical risks in organisations and institutions. Many of these assessments do not only differ in scope but also in approach. Some assessments are merely tick boxes of compliance, whereas others focus on the assessment of employee ethical behaviour in the workplace. Therefore, the type of assessments vary from conducting interviews, doing self-assessments, compiling risk registers to completing risk and ethics surveys.

However, in many instances when ethical assessments are conducted general surveys are mostly used that includes a variety of different ethical items and open questions, but often in an unstructured, and non-scientific manner. These responses are then manually configured to get some indication of unethical patterns and tendencies, supported by elementary statistics such as descriptive statistics on item level. However, no attempt thus far has been made to empirically conceptualise such an assessment against recognised ethical constructs and dimension. Attempts to standardisation such an assessment for higher education will allow for much more accurate and focussed ethical assessments and evaluation.

To summarise, ethical risk assessment is an important aspect, and it should be done in such a manner that the results are regarded as valid and reliable, and the only way to do that, is to do that in a consistent and conceptually justifiable manner. Very little empirical work has been done in this area, which is often neglected or reduced to a mere check list of ethical risks 
or unstandardized surveys with very little construct validity and reliability.

\section{PURPOSE}

This research aims to examine an ethical risk assessment done in higher education against existing ethical theories and literature, and to provide a scientifically confirmed framework which could be used by institutions to base their ethical risk assessment on.

\section{EVALUATING-ASSESSING ETHICS}

To gain more insight into understanding the components of an ethical risk assessment consideration should be given to the underlying theories of ethics. Although scholars in the field of business ethics previously made use of many different approaches and methods to understand ethical conduct in the workplace, two distinct multidimensional constructs, namely ethical climate and ethical culture, have been singled out as the most prevalent constructs to assess and evaluate ethics (McCabe, Trevino and Butterfield 2001). Ethical climate is described as the shared overall feelings and perceptions of employees of what is considered right and wrong in the workplace. These feelings and perceptions are informed by the way the organisation and or its subsystems deal with ethical issues (Cullen, Victor and Stephens 1987; Hellriegel and Slocum 1974). Ethical cultures, on the other hand, are those elements that stimulate ethical conduct and attempt to gain insight into the values, believes and assumptions held by employees (Kaptein 2008). Ethical culture can therefore exert powerful influence on employee behaviour and can also help employees to distinguish what behaviour is acceptable (right) or unacceptable (wrong) in an organisation (Martin and Siehl 1983). Ethical culture is also instrumental in nature and is driven by cultural systems that include codes of ethics, leadership, structures, rewards systems and training programmes (McCabe et al 2001).

Ethical culture and climate are in many instances used interchangeability to examine the internal ethical, social, psychological environment of organisations (Denison 1996). Studies conducted by McCabe et al. (2001) looked at the similarities of ethical climate and culture and found a strong overlap and important relationship between these two constructs. Putranta (2008) points out that the difference lies in the level of examination. Climate being more descriptive in nature and culture being much more evaluative and situational dependent (Van Oosterhout, Heugens and Kaptein 2006).

The seminal work by Victor and Cullen (1988) provides a sound theoretical basis to understand ethical climate from different perspectives. These authors have contested that different multiple ethical climates exist in organisations based on two core dimensions. The 
first dimension of their model refers to the considerations taken into account when individuals make ethical decisions.

The basis of this dimension is embedded in three recognised ethical theories, namely egoism (decisions associated with one’s own self-interest, benevolence), utilitarianism (interest of others) and principled centred deontology (upholding core principles). The second dimension is embedded within the theory of sociology and poses a distinction of locus that shapes the behaviours and attitudes of incumbents in a social system (Merton 1968). Gouldner (1957) applied this locus within an organisational context and explained that on the local level incumbents' behaviours are shaped based on the organisation's ethical policies, standards and procedures) whereas on the cosmopolitan level the incumbent is influenced and effected by laws, codes and religious values formed outside the organisation. A third locus was added by Victor and Cullen (1988) based on the work of Gouldner to also include the individual self (individuals' own personal ethics). Nine ethical climates are proposed by Victor and Cullen (1987) as indicated in Table 1.

Table 1: Ethical climate criteria

\begin{tabular}{|c|c|c|c|}
\hline Ethical criteria & Locus of analysis & Climate type & Descriptions \\
\hline Egoism & Individual & Self-interest & $\begin{array}{l}\text { Maximisation of self interest } \\
\text { Focus is on personal gain }\end{array}$ \\
\hline Egoism & Local & Company interest & $\begin{array}{l}\text { Benefit to the organisation such as } \\
\text { corporate profit }\end{array}$ \\
\hline Egoism & Cosmopolitan & Efficiency & $\begin{array}{l}\text { Benefit to the larger and or } \\
\text { economical system's interest }\end{array}$ \\
\hline Benevolence & Individual & Friendship & $\begin{array}{l}\text { Consideration for others without } \\
\text { reference to the organisation }\end{array}$ \\
\hline Benevolence & Local & Team play & $\begin{array}{l}\text { Consideration for others with } \\
\text { reference to the organisation such } \\
\text { as esprit de corps }\end{array}$ \\
\hline Benevolence & Cosmopolitan & Social responsibility & $\begin{array}{l}\text { Considered for others outside the } \\
\text { organisation - being socially } \\
\text { responsible }\end{array}$ \\
\hline Principle & Individual & Personal morality & $\begin{array}{l}\text { Organisation members guided by } \\
\text { own personal ethics }\end{array}$ \\
\hline Principle & Local & Rules and procedure & $\begin{array}{l}\text { Members are guided by } \\
\text { organisational policies and codes }\end{array}$ \\
\hline Principle & Cosmopolitan & $\begin{array}{l}\text { The law or professional } \\
\text { codes }\end{array}$ & $\begin{array}{l}\text { Members are guided by sources } \\
\text { outside the organisation such as } \\
\text { professional codes, legal } \\
\text { requirements and professional } \\
\text { codes }\end{array}$ \\
\hline
\end{tabular}

Source: Victor and Cullen $(1987,56)$

Past research on ethical culture has provided limited and mixed results and explanations of what the construct ethical culture is (Trevino and Youngblood 1990). Kaptein (2008) conducted empirical work on ethical culture and empirically tested and developed an ethical virtues model which provides descriptive normative criteria of the construct. Kaptein's model is mostly grounded in the virtue-based theory (Solomon 2004) and is the only empirical work that 
provides more clarity on ethical organisational culture. The basic assumption of this model is that the existence of corporate ethical virtues is part of the organisational conditions (culture) to act ethically (Kaptein 2008). The seven virtues in Table 2 describe an ethical culture and are grouped into self-regulating, self-providing and self-correcting capacities of the organisation.

Table 2: Ethical virtue cultures

\begin{tabular}{|l|l|l|}
\hline Capacity & Virtue & Description \\
\hline $\begin{array}{l}\text { Self- } \\
\text { regulating } \\
\text { capacity }\end{array}$ & $\begin{array}{l}\text { The organisational } \\
\text { virtue }\end{array}$ & $\begin{array}{l}\text { The organisation is very clear about its ethical standards and provides } \\
\text { a guiding organisational frame of reference for the type of ethical } \\
\text { conduct that is acceptable. }\end{array}$ \\
\cline { 2 - 3 } & $\begin{array}{l}\text { The organisational } \\
\text { virtue of congruency }\end{array}$ & $\begin{array}{l}\text { Management actions and behaviours (supervisors and senior } \\
\text { managers) are consistent and congruent with ethical standards and } \\
\text { norms of the organisation and an example is set through them. }\end{array}$ \\
\hline $\begin{array}{l}\text { Self- } \\
\text { providing } \\
\text { capacity }\end{array}$ & $\begin{array}{l}\text { The organisational } \\
\text { virtue of feasibility }\end{array}$ & $\begin{array}{l}\text { Employees' tasks and responsibilities regarding pressure, targets, } \\
\text { budgets, equipment, information and authority must be reasonable and } \\
\text { feasible }\end{array}$ \\
\cline { 2 - 3 } & $\begin{array}{l}\text { The organisational } \\
\text { virtue of } \\
\text { supportability }\end{array}$ & $\begin{array}{l}\text { The amount of support the organisation creates among employees to } \\
\text { meet normative expectations. Motivated and satisfied staff who are } \\
\text { treated fairly are more likely to act ethically in a high trust and healthy } \\
\text { work environment. }\end{array}$ \\
\hline $\begin{array}{l}\text { Self- } \\
\text { correcting } \\
\text { capacity }\end{array}$ & $\begin{array}{l}\text { The organisational } \\
\text { virtue of } \\
\text { transparency }\end{array}$ & $\begin{array}{l}\text { Employees must be aware that the nature of their actions and conduct } \\
\text { has consequences through their managers, peers, co-workers and } \\
\text { subordinates. Transparency serves to expose unethical conduct but } \\
\text { also works as a deterrent. }\end{array}$ \\
\cline { 2 - 3 } & $\begin{array}{l}\text { The organisational } \\
\text { virtue of } \\
\text { discussability }\end{array}$ & $\begin{array}{l}\text { The opportunity employees have to raise and discuss ethical issues } \\
\text { through safely reporting unethical behaviour. }\end{array}$ \\
\cline { 2 - 3 } & $\begin{array}{l}\text { The organisational } \\
\text { virtue of } \\
\text { sanctionability }\end{array}$ & $\begin{array}{l}\text { Rewarding ethical conduct and punishing unethical conduct promote } \\
\text { ethical conduct. }\end{array}$ \\
\hline
\end{tabular}

Source: Kaptein 2008, 923

The constructs culture and climate will therefore be used to conceptualise the evaluation and assessment of this ethical risk assessment.

\section{METHOD}

A discussion of the research design, the sampling method and the instrument used during the survey will follow. The statistical analysis methods - specifically explorative and confirmatory factor analysis and the process followed will be explained thoroughly.

\section{RESEARCH DESIGN}

A survey strategy was chosen for the purpose of this research. This entailed a cross-sectional design, where different samples of the total population were studied at the same time (Elmes, Kantowits and Roediger 2011, 289). This design is applicable when an attempt is made to determine the links between the variables in a population and information is gathered to analyse the population at that specific point in time. According to Elmes et al. $(2011,289)$ this design is 
ideal for descriptive and predictive functions. On the basis of this information, the course of the phenomenon is determined and the factors that influence it are established.

\section{SAMPLE}

The population consisted of \pm 3000 academic and non-academic employees in a specific ODL HEI. All the employees were invited to participate in the initial survey, resulting in a sample of 1687 respondents. The frequencies of the characteristics of this sample are indicated in Table 3.

Table 3: Frequencies of the characteristics of the sample

\begin{tabular}{|c|c|c|c|}
\hline \multicolumn{2}{|l|}{ Category } & \multicolumn{2}{|c|}{$\begin{array}{l}\text { Combined } \\
(N=1687)\end{array}$} \\
\hline & & \multirow{2}{*}{$\begin{array}{c}n \\
966\end{array}$} & \multirow{2}{*}{$\begin{array}{c}\% \\
59.2\end{array}$} \\
\hline Gender & Male & & \\
\hline$(N=1632)$ & Female & 666 & 40.8 \\
\hline \multirow{11}{*}{$\begin{array}{l}\text { Position } \\
(N=1680)\end{array}$} & Top management (VC / PVC / VPs / Registrar) & 3 & 0.2 \\
\hline & Middle management (Executive Dean / Executive Director, etc) & 17 & 1.0 \\
\hline & Operational management (HOD / Director) & 101 & 6.0 \\
\hline & Professor & 82 & 4.9 \\
\hline & Associate professor & 82 & 4.9 \\
\hline & Senior lecturer & 162 & 9.6 \\
\hline & Lecturer & 164 & 9.8 \\
\hline & Junior lecturer & 46 & 2.7 \\
\hline & Tutor & 2 & 0.1 \\
\hline & Professional / administrative / supportive / auxiliary & 833 & 49.6 \\
\hline & Employee (other) & 188 & 11.2 \\
\hline \multirow{7}{*}{$\begin{array}{l}\text { Education } \\
(N=1650)\end{array}$} & Lower than matric (grade 12) & 205 & 12.4 \\
\hline & Matric (grade 12) & 306 & 18.5 \\
\hline & Post-school diploma & 150 & 9.1 \\
\hline & Bachelor's degree & 267 & 16.2 \\
\hline & Honours degree & 196 & 11.9 \\
\hline & Master's degree & 205 & 12.4 \\
\hline & PhD degree & 321 & 19.5 \\
\hline
\end{tabular}

\section{MEASURING INSTRUMENT}

The Ethics Risk Questionnaire (ERQ) consisting of 64 items was administered to measure the climate with specific reference to the ethical risks in an open distance learning higher education institution (section A of the questionnaire). The questionnaire was developed by a reputable and well-known organisation, namely the Ethics Institute of South Africa and is mainly used (after customisation for the client) to measure ethical risks.

The questionnaire was administered in English only. A five-point Likert-type scale was used in the questionnaire with $1=$ 'strongly disagree' and $5=$ 'strongly agree', and an option 
of $\mathrm{Dk}=$ 'don't know'. In order to limit response bias, positively and negatively worded questions were included. The statistical analysis was performed by using the Statistical Package for the Social Sciences (SPSS 23). Cronbach alpha coefficients, interim correlations as well as explorative and confirming factor analysis were done to determine the validity and reliability of the instrument. The suitability of the data needed to be tested before performing factor analysis. Firstly, this involved the sample size, secondly, the strength of the relationship between the variables, and lastly, the linearity of the relationship between the variables.

In the first step, during the evaluation of the sample size, it was noted that the sample consisted of 1687 respondents that responded to a 64 item survey (item to respondent ratio of $\pm 1: 26)$. This implies an adequate sample size according to Meyers, Gamst and Guarino (2013, 687) as well as Tabachnick and Fidell (2007, 613). Secondly, the inter-correlations between items were inspected through the Bartlett's test of sphericity (Hair, Black, Babin and Anderson $2010,104)$. With this test, the statistic generated should be significant $(p<0.05)$ for exploratory factor analysis to be considered an appropriate technique (Hair et al. 2010, 104). Thirdly, the Kaiser-Meyer-Olkin (KMO) measure was used to quantify whether the items correlated sufficiently in order to determine whether a factor analysis could be performed. The minimum level set for this statistic is 0.6 (Tabachnick and Fidell 2007, 615) on the scale of 0 to 1 (Pallant 2010, 183).

To aid in the interpretation of the initial results, an oblique rotation-specifically Promax rotation was performed. The decision regarding the number of variables (factors) to be retained was based on the Guttman-Kaiser eigenvalue greater-than-one rule (K1 rule) together with the scree plot (with specific reference to the shape of the curve) and lastly the Monte Carlo PCA for parallel analysis. Meyers et al. $(2013,677)$ indicate that a guide for variance accounted for by the factors needs to meet the lower limit of 50 per cent.

The Cronbach alpha coefficients were calculated and these calculations are an indication of the proportional variance error and the internal consistency of a scale.

To operationalise this construct definition a higher order, multidimensional model of the ethical risk construct by means of confirmatory factor analysis was conducted. The confirmatory factor analysis is intended to examine whether a second-order ethical risk factor existed and whether it explained the relationships among the three lower order factors (as identified by the exploratory factor analysis) with AMOS maximum likelihood procedure (Byrne 2010). To assess the model fit, several fit indexes were used including Comparative Fit Index (CFI) Root Mean Square Error of Approximation (RMSEA), chi-square ( $\left.\chi^{2}\right)$, and the ratio of the differences in chi-square to the differences in degrees of freedom $\left(\chi^{2} / \mathrm{df}\right)$. Given that 
there is no one acceptable cut-off value of what constitutes adequate fit, it was elected to use a CFA value of 0.90 and an RMSEA value of 0.05 or less as indicative of adequate fit. For $\chi 2 / \mathrm{df}$, a ratio of less than 5.00 was interpreted as a good fit (Byrne 2010).

The first was a one factor model, in which all the items identified through the exploratory factor analysis, were indicative of one larger ethical risk factor. The second was a first-order factor model in which items were allowed to load onto their respective factors (i.e. institutional ethical leadership orientation, individual lemployee ethical orientation and institutional studentcenteredness lorientation) and the factors allowed to correlate with each other. The third was a second-order factor model in which items were loaded onto their respective factors and the three factors loaded on a second-order latent ethical risk factor.

\section{RESULTS}

In order to determine the suitability and appropriateness of a factor analysis on the dataset, Bartlett's test of sphericity and the KMO were performed. The significance of Bartlett's test of sphericity was $p \leq .001$, which was higher than the set margin of $p<.05$, and the KMO value was 0.87 , which was higher than the critical value of 0.6 . Meeting these criteria implied adequate correlation among items to perform an exploratory factor analysis.

First-order factor withdrawal was done on the 64 items using SPSS 23. Seven factors with eigenvalues larger than one were identified.

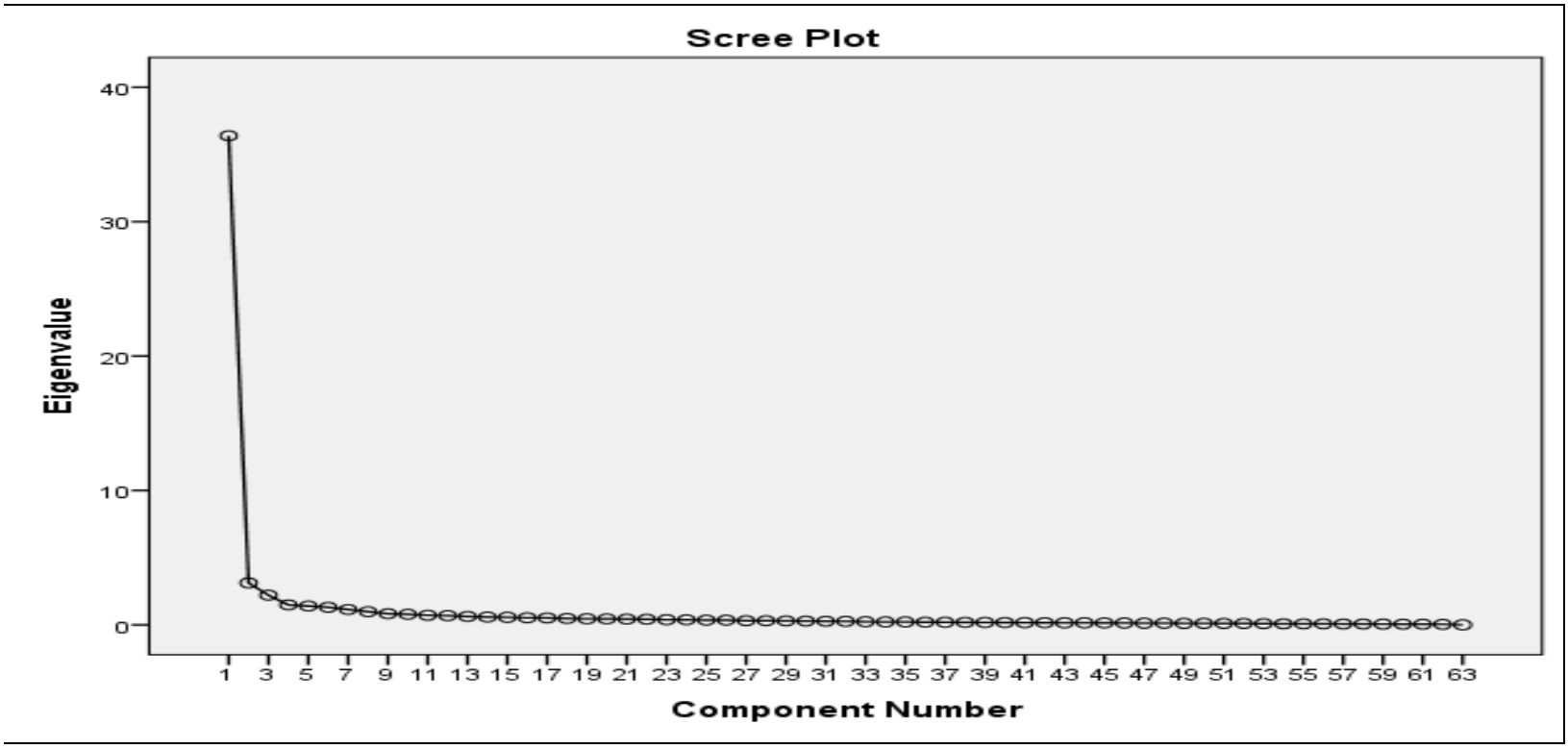

Figure 1: Scree plot

Although the scree plot levelled off sharply to the right after the fourth factor (see Figure 1) all seven factors were included in the factor structure further tested through the Monte Carlo 
principle component parallel analysis (Pallant 2010, 185). The results are reported in Table 4.

Table 4: Results of the Monte Carlo parallel analysis

\begin{tabular}{|c|c|c|c|}
\hline $\begin{array}{c}\text { Component } \\
\text { number }\end{array}$ & Actual eigenvalues from PCA & $\begin{array}{c}\text { Criterion value from parallel } \\
\text { analysis }\end{array}$ & Decision \\
\hline 1 & 36.39 & 1.67 & accept \\
\hline 2 & 3.12 & 1.55 & accept \\
\hline 3 & 2.21 & 1.53 & accept \\
\hline 4 & 1.48 & 1.50 & reject \\
\hline 5 & 1.40 & 1.47 & reject \\
\hline 6 & 1.31 & 1.39 & reject \\
\hline 7 & 1.14 & 1.28 & reject \\
\hline
\end{tabular}

The results of the Monte Carlo parallel analysis yielded a three-factor model. The three factors accounted for 66.2 per cent of the total variance, with factor ${ }^{1-3}$ accounting for 57.76, 4.95 and 3.50 variance respectively.

Based on the subscales (factors) that are said to comprise the Ethical Risk Questionnaire (ERQ) many correlations between the pairs of factors were in excess of 0.6 (see Table 8), strongly suggesting the appropriateness of an oblique rotation strategy; thus, Promax rotation was used.

The results of the oblique method and Promax rotation for each of the three factors are summarised in Tables 5, 6 and 7. These tables include the factor loadings, commonalities, percentage variation of the first-order factor withdrawal and Promax rotation of the three respective factors, including the descriptive statistics and psychometric properties.

Table 5: Factor 1 Institutional ethical leadership orientation

\begin{tabular}{|c|l|c|c|c|c|}
\hline $\mathbf{N r}$ & \multicolumn{1}{|c|}{ Item } & $\begin{array}{c}\text { Factor } \\
\text { loading }\end{array}$ & $\boldsymbol{h}^{\mathbf{2}}$ & Mean & $\begin{array}{c}\text { Std. } \\
\text { Deviation }\end{array}$ \\
\hline 23 & Organisational politics undermine ethics & 0.86 & 0.52 & 3.10 & 1.24 \\
\hline 36 & Unrealistic demands on employees' time/resources & 0.84 & 0.50 & 3.27 & 1.29 \\
\hline 31 & Employees are not consulted regarding change initiatives & 0.83 & 0.46 & 2.87 & 1.39 \\
\hline 62 & $\begin{array}{l}\text { Animosity/conflict between administrative and academic } \\
\text { staff }\end{array}$ & 0.83 & 0.40 & 3.04 & 1.26 \\
\hline 16 & Unfair working conditions & 0.82 & 0.38 & 3.37 & 1.39 \\
\hline 22 & $\begin{array}{l}\text { Management restricts the academic freedom that } \\
\text { academics are entitled to }\end{array}$ & 0.80 & 0.43 & 3.24 & 1.17 \\
\hline 53 & Unfair budget allocation between divisions/departments & 0.79 & 0.38 & 3.27 & 1.00 \\
\hline 7 & Inadequate communication to employees & 0.78 & 0.43 & 3.10 & 1.38 \\
\hline 44 & Autocratic management style & 0.77 & 0.52 & 3.02 & 1.33 \\
\hline 8 & Favouritism & 0.77 & 0.51 & 2.83 & 1.45 \\
\hline 58 & Abuse of power by management & 0.76 & 0.59 & 2.95 & 1.29 \\
\hline 21 & $\begin{array}{l}\text { Performance targets being viewed as more important } \\
\text { than ethics }\end{array}$ & 0.74 & 0.44 & 2.89 & 1.31 \\
\hline 49 & Abusive/disrespectful treatment of staff & 0.74 & 0.55 & 3.34 & 1.28 \\
\hline 51 & Employees take credit for colleagues' work & 0.73 & 0.50 & 3.08 & 1.23 \\
\hline 55 & Deliberately withholding information from staff & 0.72 & 0.54 & 3.30 & 1.19 \\
\hline 33 & Nepotism (preferential treatment for family/ friends) & 0.72 & 0.46 & 2.87 & 1.30 \\
\hline 57 & Unfair reward systems & 0.71 & 0.50 & 2.66 & 1.28 \\
\hline
\end{tabular}




\begin{tabular}{|c|l|c|c|c|c|}
\hline $\mathbf{N r}$ & \multicolumn{1}{|c|}{ Item } & $\begin{array}{c}\text { Factor } \\
\text { loading }\end{array}$ & $\boldsymbol{h}^{2}$ & Mean & $\begin{array}{c}\text { Std. } \\
\text { Deviation }\end{array}$ \\
\hline 42 & Workplace bullying & 0.67 & 0.51 & 2.86 & 1.31 \\
\hline 14 & Political interference in the running of the university & 0.63 & 0.50 & 3.34 & 1.27 \\
\hline 50 & Squandering money on unnecessary things & 0.63 & 0.55 & 2.97 & 1.26 \\
\hline 26 & Unrealistic expectations regarding research output & 0.60 & 0.44 & 3.26 & 1.18 \\
\hline 52 & Undue pressure to publish & 0.60 & 0.44 & 3.18 & 1.13 \\
\hline 59 & Disrespect for the confidentiality of information & 0.59 & 0.54 & 3.54 & 1.15 \\
\hline 60 & Low standards for the admission of students & 0.57 & 0.40 & 3.10 & 1.33 \\
\hline 32 & Plagiarism by students & 0.56 & 0.38 & 3.08 & 1.12 \\
\hline 4 & Workplace bullying & 0.55 & 0.46 & 3.33 & 1.41 \\
\hline 41 & Pressure to compromise academic standards & 0.55 & 0.53 & 3.22 & 1.26 \\
\hline 28 & $\begin{array}{l}\text { Inconsistent application of discipline of employees who } \\
\text { transgress rules }\end{array}$ & 0.55 & 0.49 & 3.08 & 1.25 \\
\hline 46 & Lack of personal responsibility and accountability & 0.52 & 0.52 & 3.17 & 1.31 \\
\hline 61 & Lack of accessibility of lecturing staff & 0.48 & 0.34 & 3.06 & 1.23 \\
\hline 43 & Disregard for the natural (physical) environment & 0.48 & 0.38 & 3.75 & 1.13 \\
\hline 38 & Inappropriate relations with political/regulatory entities & 0.46 & 0.45 & 3.78 & 0.95 \\
\hline & Percentage variance & $37.01 \%$ & & & \\
\hline & Mean (I5) $\quad$ Std. Deviation & -.32 & & 0.98 \\
\hline
\end{tabular}

Table 6: Factor 2 Individuallemployee ethical orientation

\begin{tabular}{|c|c|c|c|c|c|c|c|}
\hline $\mathrm{Nr}$ & \multicolumn{3}{|c|}{ Item } & $\begin{array}{l}\text { Factor } \\
\text { loading }\end{array}$ & $h^{2}$ & Mean & $\begin{array}{c}\text { Std. } \\
\text { Deviation }\end{array}$ \\
\hline 9 & \multicolumn{3}{|c|}{ Sexual harassment of students } & 0.93 & 0.42 & 4.63 & 0.60 \\
\hline 10 & \multicolumn{3}{|c|}{ Asking students for bribes } & 0.92 & 0.48 & 4.67 & 0.61 \\
\hline 12 & \multicolumn{3}{|c|}{ Discrimination against students on the basis of gender } & 0.92 & 0.38 & 4.61 & 0.71 \\
\hline 34 & \multicolumn{3}{|c|}{ Accepting bribes from students in return for favours } & 0.90 & 0.50 & 4.48 & 0.68 \\
\hline 15 & \multicolumn{3}{|c|}{ Discrimination against students based on race/colour } & 0.82 & 0.42 & 4.00 & 1.14 \\
\hline 64 & \multicolumn{3}{|c|}{ Sexual harassment of employees } & 0.74 & 0.38 & 4.30 & 0.68 \\
\hline 35 & \multicolumn{3}{|c|}{ Inappropriate acceptance of gifts by employees } & 0.70 & 0.50 & 4.24 & 0.80 \\
\hline 6 & \multicolumn{3}{|c|}{ Theft of the university's property } & 0.62 & 0.52 & 3.73 & 1.14 \\
\hline 5 & \multicolumn{3}{|c|}{ Discrimination against employees on the basis of gender } & 0.61 & 0.39 & 3.81 & 1.23 \\
\hline 11 & \multicolumn{3}{|c|}{ Accepting bribes/kickbacks from suppliers/contractors } & 0.54 & 0.50 & 4.29 & 0.90 \\
\hline 24 & \multicolumn{3}{|l|}{ Fraud } & 0.53 & 0.56 & 3.78 & 1.03 \\
\hline 63 & \multicolumn{3}{|c|}{$\begin{array}{l}\text { Prospective employees presenting falsified previous } \\
\text { qualifications when applying for jobs at the university }\end{array}$} & 0.52 & 0.43 & 3.76 & 0.83 \\
\hline 17 & \multicolumn{3}{|c|}{ Plagiarism by members of staff } & 0.52 & 0.45 & 3.89 & 0.98 \\
\hline 54 & \multicolumn{3}{|c|}{ Disrespectful treatment of suppliers } & 0.46 & 0.33 & 4.05 & 0.76 \\
\hline 30 & \multicolumn{3}{|c|}{ Non-procedural procurement practices } & 0.46 & 0.43 & 3.77 & 0.96 \\
\hline 25 & \multicolumn{3}{|c|}{$\begin{array}{l}\text { Discrimination against employees on the basis of } \\
\text { race/colour }\end{array}$} & 0.43 & 0.43 & 3.24 & 1.42 \\
\hline \multicolumn{4}{|c|}{ Percentage variance } & $37.01 \%$ & & & \\
\hline \multicolumn{2}{|r|}{ Mean (/5) } & Std. Deviation & Skewness & Kurtosis & \multicolumn{3}{|c|}{$\alpha$} \\
\hline & 4.10 & 0.59 & -.87 & 1.8 & \multicolumn{3}{|c|}{0.9} \\
\hline
\end{tabular}

Table 7: Institutional student-centerednesslorientation

\begin{tabular}{|c|l|c|c|c|c|}
\hline No & \multicolumn{1}{|c|}{ Item } & $\begin{array}{c}\text { Factor } \\
\text { loading }\end{array}$ & $\boldsymbol{h}^{\mathbf{2}}$ & Mean & $\begin{array}{c}\text { Std. } \\
\text { Deviation }\end{array}$ \\
\hline 1 & Deliberately lying to or misleading students & 0.88 & 0.69 & 4.27 & 0.98 \\
\hline 2 & Withholding crucial information from students & 0.79 & 0.56 & 4.15 & 1.05 \\
\hline 29 & Promises to students are not kept & 0.67 & 0.40 & 3.32 & 1.22 \\
\hline 47 & Poor service delivery to students & 0.60 & 0.49 & 2.94 & 1.30 \\
\hline
\end{tabular}




\begin{tabular}{|c|c|c|c|c|c|c|c|}
\hline No & \multicolumn{3}{|c|}{ Item } & $\begin{array}{c}\text { Factor } \\
\text { loading }\end{array}$ & $h^{2}$ & Mean & $\begin{array}{c}\text { Std. } \\
\text { Deviation }\end{array}$ \\
\hline 40 & \multicolumn{3}{|c|}{ Students deprived of access to information } & 0.56 & 0.37 & 3.89 & 1.13 \\
\hline 3 & \multicolumn{3}{|c|}{ Admitting more students than the institution can handle } & 0.54 & 0.46 & 2.87 & 1.42 \\
\hline 39 & \multicolumn{3}{|c|}{ Arrogance towards students } & 0.53 & 0.46 & 3.64 & 1.18 \\
\hline 20 & \multicolumn{3}{|c|}{ Treating students disrespectfully } & 0.49 & 0.52 & 3.93 & 1.15 \\
\hline \multicolumn{4}{|c|}{ Percentage variance } & $37.01 \%$ & & & \\
\hline \multicolumn{2}{|r|}{ Mean (I5) } & $\begin{array}{c}\text { Std. } \\
\text { Deviation }\end{array}$ & Skewness & Kurtosis & \multicolumn{3}{|c|}{$\alpha$} \\
\hline & 3.62 & 0.84 & -0.49 & 0.02 & \multicolumn{3}{|c|}{0.90} \\
\hline
\end{tabular}

Meyers et al. (2013, 680) and Hair et al. (2010, 117) recommend significant factor loadings (based on the sample size) and therefore items with factor loadings lower than 0.40 were deleted in Tables 5, 6 and 7 above. The criteria of a factor loading cut-off point of 0.40 for inclusion in the interpretation of a factor (Hair et al. 2010, 117; Meyers et al. 2013, 680) resulted in 56 items (of the original 64 items) included in the instrument with significant factor loadings on three factors. $\mathrm{F}^{\mathbf{1}}$ (Institutional ethical leadership orientation), $\mathrm{F}^{\mathbf{2}}$ (Individual $\backslash$ employee ethical orientation) and $\mathrm{F}^{3}$ (Institutional student-centerednesslorientation) had 32, 16 and 8 items respectively that met the criteria.

The communalities $\left(\mathrm{h}^{2}\right)$ of the three factors, reported in Tables 5, 6 and 7 were relatively high. The Cronbach alpha coefficients $(\alpha)$ of the factors were acceptable (ranging from .90 to .98) when the guideline of $\alpha>.70$ (Nunnally and Bernstein 1994) was applied. It would thus appear that the factors had acceptable levels of internal consistency. The inter-correlation matrix of the newly developed organisational climate questionnaire with a three-factor structure is summarised in Table 8.

Table 8: Correlation matrix

\begin{tabular}{|l|c|c|c|}
\hline & $\begin{array}{c}\text { Institutional } \\
\text { ethical } \\
\text { leadership } \\
\text { orientation }\end{array}$ & $\begin{array}{c}\text { Institutional student- } \\
\text { centerednesslorientation }\end{array}$ & $\begin{array}{c}\text { IndividuallEmployee } \\
\text { ethical orientation }\end{array}$ \\
\hline $\begin{array}{l}\text { Institutional ethical } \\
\text { leadership orientation }\end{array}$ & 1 & 1 & \\
\hline $\begin{array}{l}\text { Institutional student- } \\
\text { centerednesslorientation }\end{array}$ & $0.78^{* *}$ & $0.68^{* *}$ & \multirow{2}{*}{1} \\
\hline $\begin{array}{l}\text { Individuallemployee } \\
\text { ethical orientation }\end{array}$ & $0.74^{* *}$ & \multirow{2}{|c|}{$: p \leq .001$} \\
\hline
\end{tabular}

The correlations in Table 8 indicate the inter-factor correlations between the three-factor structures. Institutional ethical leadership orientation correlated with Institutional studentcenteredness lorientation, (0.78) and Individual \employee ethical orientation (0.74), while the correlation between Institutional student-centerednesslorientation and Individuallemployee 
ethical orientation, was 0.68 .

In order to validate the ethical risk structure (the three factors as identified with the exploratory factor analysis described above) a confirmatory factor analysis was conducted. The results in terms of the three models tested are reported in Table 9, specifically concerning the respective fit indexes (Comparative Fit Index, Root Mean Square Error of Approximation, chisquare and the ratio of the differences in chi-square to the differences in degrees of freedom).

Table 9. Comparison of a priori ethical risk questionnaire factor structure

\begin{tabular}{|c|c|c|c|c|c|c|}
\hline Structure & $x^{2}$ & df & $\mathrm{x} 2 / \mathrm{df}$ & $\Delta \mathrm{x}^{2}$ & CFI & RMSEA \\
\hline One-factor model (all 56 items) ${ }^{*}$ & 15890 & 1484 & 10.71 & & 0.61 & 0.076 \\
\hline First-order factor model $\mathbf{b}$ & 6509 & 1335 & 4.88 & $9381 \mathrm{a-b}{ }^{* *}$ & 0.902 & 0.048 \\
\hline Second-order factor model $l_{c}$ & 6894 & 1336 & 5.16 & $385_{c-b}{ }^{* \star}$ & 8.95 & 0.048 \\
\hline
\end{tabular}

All chi-square values are significant at $p<.001$; the $\Delta x 2$ is in relation to one-factor model.

$\mathrm{CFI}=$ comparative fit index; RMSEA = root mean square error of approximation.

*: The 56 items (from 64) as determined by the exploratory factor analysis

${ }^{* *}: p<.01$ (two-tailed).

The worst-fitting model is the one-factor model in which all 56 items (as identified by means of the exploratory factor analysis) items were loaded directly on a single-factor ethical risk assessment, as demonstrated by the relatively poor fit indexes. Assessing whether the secondorder factor model is significantly better than the first-order factor model was done using a chisquare test. The difference in chi-square between the first-order factor and second-order factor models is 385 (i.e. 6 894-6 509) which is distributed as chi-square with $(1336-1335=1)$ degrees of freedom. The fact that this value is statistically significant would suggest that the first order factor model (with factors Institutional ethical leadership orientation, Individual/employee ethical orientation and Institutional student-centeredness/orientation) is significantly better than the second order factor model, which includes these three factors but a higher order or second order factor, called Ethical risk.

The results illustrate that the best-fitting model is the first-order factor model which is a confirmation of the exploratory factor analysis results. The fit statistics represent a considerable improvement in the chi-square, CFIs, and RMSEAs over the one-factor model (modela) and to some extent the second-order factor (modelc) and thus suggest that the first-order factor model (modelb) as determined by the exploratory factor analyses, and now confirmed through the confirmatory factor analysis is preferable.

\section{DISCUSSION}

The results of the factor analysis allow for much interpretation. The conceptualisation of the three factors identified in this analysis will be discussed against the theoretical grounding of the 
seminal work done on culture and climate.

\section{Institutional ethical leadership orientation}

The recent emergence of ethical leadership as a recognised leadership theory especially in the midst of continued corporate scandals, management wrong doing and societal challenges attest to the relevance and importance of this construct (Yukl 2013). Institutional ethical leadership orientation is embedded in the virtue of congruency and requires all managers and leaders in the organisation to act congruent with the institution's ethical codes and values. The importance of having visible role models that set the tone for ethical conduct and standards cannot be underestimated in the process of institutionalising ethics in the institution (Brown, Trevino and Harrison 2005). Kaptein (2008) found that in many instances unethical conduct is more prevalent when managers and leaders in the organisation engage themselves in unethical conduct. Thus the importance of authentic leadership behaviour across the organisation is central to building a culture of integrity and trust in the organisation. As Goodpaster (2007) points out that leaders in the organisation are the principal architects of corporate moral consciousness. Greenbaum, Quade and Bonner $(2015,30)$ reiterate this by stating that decision making and visible demonstration of ethical practices define the ethical character of a leader.

In many cases leaders are also confronted with the stark reality of creating and maintaining a sustainable business model. To achieve this, leaders in the institution are required to endorse a culture of efficiency and effectiveness to deliver on the institution's mandate. They expect employees to execute tasks and responsibilities by providing them with a certain amount of resources. Kaptein $(2008,925)$ points out that the intensity to make profit may compromise the ethical virtuosity of an organisation by stating that 'if employees have little or no scope to realise their tasks and responsibilities, the risk of unethical conduct increases'. Schweitser, Ordones and Douma (2004) found that pursuing excessive high targets stimulates unethical behaviour. This egocentric culture and work conditions are in many cases a compromise and an excuse not to fulfil in and comply with the organisation's ethical obligations and responsibilities. Thus, if an organisation functions with a paradigm of 'all that matters is the bottom line' whilst discarding its responsibility towards its employees and society at large its ethical egocentric actions will increase. Sustainability of any higher education institution is therefore dependent on its ability to manage all its resources in a responsible and altruistic way. This, in turn, will lead to improved institutional reputation and credibility. An ethical leadership approach has therefore been proven to be associated with much more positive organisational outcomes than other approaches (Brown and Mitchell 2010; Dane and Sonenshein 2015). 


\section{Individual/employee ethical orientation}

Employee ethical orientation centres on the concept of personal ethics. This factor is characterised by challenging one's own convictions by articulating, defending and espousing the personal values and ethical principles that define who one is. At the centre of this lies one's own moral and ethical convictions. Employees are often faced with difficult and complex ethical dilemmas that require strong personal conviction. Certain core characteristic such as personal courage and authenticity are now seen as essential personal traits to act and stand firm when challenged on important ethical matters. Employees also require having a certain amount of ethical awareness and understanding of what is expected of them in the institution. This consciousness is grounded in a thorough understanding of what constitutes sound ethical conduct whilst also having the ability to discern between ethical and unethical conduct. Theoretical underpinning of this construct is found in Victor and Cullen's ethical criteria of the adherence to principles such as company rules and procedures and Kaptein's virtue culture of clarity where employees are clear about ethical standards and conduct that should be upheld (Kaptein 2008, 925; Victor and Cullen 1988, 107). Frequent and effective communication to employees of ethical codes, policies and practices through line managers, training sessions and workshops forms the basis of this orientation. The virtues of sanctionability and transparency also play a very important role in ensuring individual accountability. Knowing that one should be consistent and transparent about one's ethical responsibility in the institution not only acts as a deterrent to getting caught for one's unethical actions but also as a medium to collectively and visibility discourage unethical conduct. In this regard one's peers, colleagues, supervisors and co-workers play a critical role in reinforcing sanctionability throughout the institution. In addition, this factor is also associated with the virtue of a culture of feasibility and supportability and Victor and Cullen's ethical criteria of benevolence for being socially responsible through one's actions. Higher education institutions are responsible to uphold values of social justice and fairness and by implication to treat all its stakeholders equal, fair and just (Soudien 2008). In this regard stakeholders can include employees, partners and suppliers. Institutional egalitarianism is in many instances evident when a strong conviction exists with employees to practise and apply ethical good practices towards each other.

\section{Institutional student-centerednesslorientation}

Student-centeredness has recently become a core factor in higher education institutions. It is embedded in Victor and Cullen ethical criteria of benevolence maximizing joint interest. In a 
public address the vice-chancellor of a leading higher education institution reminded staff members of the importance of serving students with the necessary diligence. 'Students are the primary stakeholders at the heart of an academic enterprise. Greatness or weakness of any university is judged through its performance in the area of its academic enterprise and this is an outcome of a range of factors, from excellent student support services and quality of academics mainly indicated by the quality of teaching and learning’ (Makanya 2016).

Thus the importance of providing students with access to education and the ability of the organisation to align its system and processes towards excellent service delivery is of fundamental importance and is in the interest of the institution and its students. The emergence of this factor emphasises the importance and relevance of higher education institutions to focus their efforts on students in an ethical and just way (Report on the Stakeholder Summit 2010). Some ethical aspects that could contribute towards student-centeredness include treating students with respect, providing the necessary support, upholding transparency, providing access to information and ensuring high levels of service delivery (Higher Education Service Delivery Charter 2010).

\section{FINDINGS}

The factor analysis conducted provided sufficient evidence of a factor structure to aid in the conceptualisation of this ethical risk assessment particularly in higher education. This factor structure revealed a clear distinct set of ethical core constructs that have been defined and explained based on a sound theoretical grounding. First and foremost, the three main factors identified in this study, namely institutional ethical leadership orientation, individual/employee ethical orientation and institutional student-centerednesslorientation can be compared to Victor and Cullen's $(1988,106)$ locus of analysis analogy. This analogy implies that ethical reasoning is based on different types of reference groups that help shape the ethical behaviours and attitudes within the organisation. According to the authors three different levels of analysis exist within the organisation, namely the individual, local and cosmopolitan level. On the individual level ethical reasoning is located within the individual's own needs and preferences, on the local level ethical reasoning takes place within teams and workgroups and on the cosmopolitan level consideration for ethical reasoning is based on the organisation and it's functioning within a larger social system. Rossouw and Van Vuuren (2013) also emphasise the importance of distinguishing between different levels when considering the institutionalisation of ethics in an organisation. Thus the scope of the ethical risk assessment in its current form covers a wide range of relevant and unique ethical aspects, especially relevant to higher education. 


\section{LIMITATIONS}

Recurrent limitations, as postulated by scholars conducting previous studies, should be highlighted. Firstly, there is no system to distinguish systematically between the sources, for instance, to compare top management's responses with those of their employees (Mayer, Kuensi and Greenbaum 2009). Secondly, it is acknowledged that the ethical risk assessment framework was designed to capture formal, normative systems; however, a deeper understanding of ethical risks (and climate) will emerge from analysing informal systems through triangulation (Webber 2007). Lastly, the Ethics Risk Questionnaire (ERQ) is based on self-reporting that may lead to method bias which might still be a reality, even with the assurance provided to participants during the briefing regarding anonymity as well confidentiality. Social desirability and subsequent response bias will always remain a concern and a limitation in studies like this (Fritssche 2000).

\section{CONTRIBUTION OF THE RESEARCH}

This research is the first of its kind to empirically conceptualise an ethical risk assessment for higher education institutions in South Africa. It provides a foundation for further research to validate or reject the ethical constructs found in this study. Building on this research the possibility exists to develop an empirical ethical risk assessment that can be used exclusively to assess higher education ethical climates and or culture.

\section{NOTES}

1. This study was conducted after special permission was obtained from the Ethics Institute (previously known as the Ethical Institute of South Africa [EthicsSA], and an ethical clearance certificate was issued by the Unisa Graduate School of Business Leadership Research Ethics Committee (Ref 2014_SBL_011_SD, dated 1 December 2014).

2. The Ethical Risk Assessment instrument used in this study is the property of the Ethics Institute and further reproduction is prohibited without written consent from them. The full version of the instrument can be formally requested from the Ethics Institute.

\section{REFERENCES}

Brown, M. E. and M. S. Mitchell. 2010. Ethical and unethical leadership: Exploring new avenues for future research. Business Ethics Quarterly 20: 583-616.

Brown, M. E., L. K. Treviño and D. Harrison. 2005. Ethical leadership: A social learning perspective for construct development and testing. Organisational Behavior and Human Decision Processes 97: 117-134.

Byrne, B. 2010. Structural equation modeling with AMOS: Basic concepts, applications, and programming. Mahwah, NJ: Lawrence Erlbaum Associates Publishers.

Chapman, D. W. and C-L. Chien. 2014. Graduate education in Malaysia and Thailand. In Higher education in East and South Asia: Expand out, expanding up, ed. D. W. Chapman and C-L. Chien, 33-44. Montreal: UNESCO Institute for Statistics. 
Chapman, D. W. and S. Lindner. 2016. Degrees of integrity: The threat of corruption in higher education. Studies in Higher Education 41(2): 247-268.

Cullen, J. B., B. Victor and C. Stephens. 1989. An ethical weather report: Assessing the organisation's ethical climate. Organisational Dynamics 18(2): 50-62.

Dane, E. and S. Sonenshein. 2015. On the role of experience in ethical decision making at work: An ethical expertise perspective. Organisational Psychology Review 5(1): 74-96.

Denison, D. R. 1996. What is the difference between organisational culture and organisational climate? A native's point of view on a decade of paradigm wars. Academy of Management Review 21(3): 619-654.

Elmes, D., B. Kantowits and H. Roediger. 2011. Research methods in psychology. ${ }^{\text {th }}$ Edition. Belmont, CA: Wadsworth, Cengage Learning.

Fritssche, D. J. 2000. Ethical climates and the ethical dimension of decision making. Journal of Business Management 24: 125-140.

Goodpaster, K. E. 2007. Conscience and corporate culture. Western Ontario: Blackwell Publishing.

Gouldner, A. W. 1957. Cosmopolitans and locals: Toward an analysis of latent social roles. Administrative Science Quarterly 1: 281-306.

Greenbaum, R. L., M. J. Quade and J. Bonner. 2015. Why do leaders practice a moral management: A conceptual investigation of the impediments to ethical leadership. Organisational Psychology Review 5(1): 26-49.

Hair, J. F., W. W. Black, B. J. Babin and R. E. Anderson. 2010. Multivariate data analysis. $7^{\text {th }}$ Edition. Saddle River, NJ: Prentice Hall.

Hellriegel, D. and J. W. Slocum. 1974. Organisational climate: Measures, research and contingencies. Academy of Management Journal 17(2): 255-280.

Higher Education Service Delivery Charter. 2010. http://www.dhet.gov.sa//DHET\%20Approved\%20 Service\%20Charter.pdf

Kaptein, M. 2008. Developing and testing a measure for the ethical culture of organisations: The corporate ethical virtues model. Journal of Organisational Behavior 29(7): 923-947.

Makanya, M. S. 2016. VC Address. https://staff.unisa.ac.sa/e-connect/e-news/2016/01/29/vc-outlinesunisas-future/

Martin, J. and C. Siehl. 1983. Organisational culture and counterculture: an uneasy symbiosis. Organisational Dynamics 12(2): 52-64.

Mayer, D. M., M. Kuensi and R. L. Greenbaum. 2009. Making ethical climate a mainstream management topic: A review, critique, and prescription for the empirical research on ethical climate. In Psychological perspectives on ethical behavior and decision making, ed. D. De Cremer, 181-213. Greenwich, CT: Information Age Publishing.

McCabe, D. L., L. K. Trevino and K. D. Butterfield. 2001. Dishonesty in academic environments: The influence of peer reporting requirements. Journal of Higher Education 1: 29-45.

Merton, R. K. 1968. Social theory and social structure. Enlarged Ed. Free Press. London: CollierMacmillan.

Meyers, L. S., G. Gamst and A. J. Guarino. 2013. Applied multivariate research: Design and interpretation. $2^{\text {nd }}$ Edition. Thousand Oaks, CA: SAGE.

Nunnally, J. C. and I. H. Bernstein. 1994. Psychometric theory. $3^{\text {rd }}$ Edition. New York, NY: McGrawHill.

Pallant, J. 2010. SPSS Survival Manual: A step by step guide to data analysis using SPSS for Windows. $4^{\text {th }}$ Edition. London: Open University Press.

Prisacariu, A. and M. Shah. 2016. Defining the quality of higher education around ethics and moral values. Quality in Higher Education 22(2): 152-166.

Putranta, M. P. 2008. The relationships between ethical climates, ethical ideology, and organisational commitment. Doctoral thesis, University of Notre Dame Australia, Fremantle, WA. 
Republic of South Africa. 2012. Government Gazette, Vol 569, No 35923. Pretoria: Government Printers.

Report on the Stakeholder Summit on Higher Education. 2010. http://www.dhet.gov.sa/summit/Docs/ General/he_transformation_summit_report.pdf

Rossouw, D. and L. van Vuuren. 2013. Business ethics. Oxford: Oxford University Press.

Schweitser, M. E., L. Ordóñes and B. Douma. 2004. Goal setting as a motivator of unethical behaviour. Academy of Management Journal 4(3): 422-432.

Shah, M. and S. C. Nair. 2014. Turning the ship around. Quality Assurance in Education 22(2): 14557.

Solomon, R. C. 2004. Aristotle, ethics and business organisations. Organisation Studies 25: 1021-1043.

Soudien C. 2008. Report of the Ministerial Committee on Transformation and Social Cohesion and the Elimination of Discrimination in Public Higher Education Institutions. www.uj.ac.sa/2008\%20 Ministerial\%20Report\%20on\%20Transformation.

Stakeholder Summit on Higher Education Transformation. 2010. Cape Peninsula University of Technology, Bellville campus, Cape Town.

Tabachnick, B. G. and L. S. Fidell. 2007. Using multivariate statistics. $5^{\text {th }}$ Edition. Boston: Pearson Education.

The King III Report on Corporate Governance for South Africa. 2009. The Institute of Directors in Southern Africa. September.

Trevino, L. K. and S. A. Youngblood. 1990. 'Bad apples in bad barrels: A causal analysis of ethical decision-making behaviour. Journal of Applied Psychology 75(4): 378.

Yukl, G. 2013. Leadership in organisations. University of Albany, State University of New York. Pearson Global Edition.

Van Oosterhout, J. H., P. P. Heugens and M. Kaptein. 2006. The internal morality of contracting: Advancing the contractualist endeavour in business ethics. Academy of Management Review 31(3): 521-539.

Victor, B. and J. B. Cullen. 1987. A theory and measure of ethical climate in organisations. Research in Corporate Social Performance and Policy 9(1): 51-71.

Victor, B. and J. B. Cullen. 1988. The organisational bases of ethical work climates. Administrative Science Quarterly: 101-125.

Webber, S. 2007. Ethical climate typology and questionnaire: a discussion of instrument modifications. The Journal of Academic Librarianship 33(5): 567-580. 